\title{
The Effect which Nagging has on Fast Food Purchase Intent by Tweens in Pietermaritzburg Area, South Africa
}

\author{
Maxwell Agabu Phiri \\ Dr. Maxwell Agabu Phiri is a lecturer in the School of Management of the \\ University of KwaZulu-Natal, South Africa. \\ Email:phirim@ukzn.ac.za
}

\section{Andrew Wright}

Andrew Wright is a MCom graduate from the University of KwaZulu-Natal.

Doi:10.5901/mjss.2014.v5n20p141

\section{Abstract}

\begin{abstract}
Tweens, are defined by Lindstrom $(2004,175)$ as pre-pubescent consumers who fit into the age category of 8 - 14 years old. Tweens are regarded as the richest generation of children to date, with an estimated personal expenditure of $\$ 28$ billion in the United States in 2000 (Gunter, Oats, Blades, 2005: 2). However, it is the influence which tweens exert on parental consumption which potentially makes tweens a profitable niche market. Data collected by Gunter, et al. (2005) stated that tweens were responsible for an estimated $\$ 250$ billion worth of parental expenditure due to the influence which they exert during the purchase decision making process. The research for this paper was based on a formulated questionnaire which was administered at 4 schools in the Pietermaritzburg area. The objectives of the research was: to determine how advertising appeals affect the consumption of fast food by children in the Pietermaritzburg area; to determine if any preconceived perceptions of fast food brands exist in the mindset of children; to determine the effect that age has on cognition of advertisements; and to determine the effect which the 'Nag Factor' has on consumption. Data was analysed utilising SPSS (Statistics Package for Social Sciences) and key findings were graphically represented. These findings are discussed and compared to literature. The findings of the study showed that the effects of nagging do not have a strong correlation with consumption frequency; Even though the majority of tweens (86\%) were aware of adverts, respondents who were unaware of what an advert was requested fast food at a similar frequency; During the concrete operations phase age does not have a strong correlation with nagging, but in the formal operations stage as age increases the frequency of nagging decreases.
\end{abstract}

Keywords: Tweens, Nag effect, personal consumption, advertising.

\section{Introduction}

The South African fast food industry has shown that there was a positive growth during the 2009 fiscal year with an annual increase of $9.6 \%$ for January 2009 relative to January 2008 (StatsSA, 2009: 3). Meanwhile, tweens have been described as a profitable market not only to due to personal consumption, but also because of the influence which they exert on parental consumption (Gunter, et al., 2005: 2). However, little research has been conducted on the impact of nagging within the South African fast food industry. The aim of this paper is to discuss the effect which nagging has on fast food purchase intent by tweens in Pietermaritzburg

\section{Main Research Problem}

Little research has been conducted which can be used to determine the effect which nagging has on consumption frequency of fast food by children in South Africa and in the Pietermaritzburg area in particular.

\subsection{Research Question}

The following research questions were outlined for the study in order to reach the desired goals:-

Is there a relationship between consumption frequency and who requests fast food?

Does age play a role in the frequency of nagging by children?

Does the use of adverts on children who do not fully understand the purpose of advertisements result in 
exacerbated nagging?

\section{Literature Survey}

\subsection{The Nag Effect}

The "Nag effect" (which is also referred to as Pester-Power) is described by Phillips (1999: 1 ) as the different buying styles which parents respond to with regard to consistent nagging from their children. Phillips (1999: 1) found that "Kids are critical to the whole purchasing process". A study which was conducted by Cheryl Idell entitled "The Nag Effect" and is documented in Hamilton (2006: 7) found that there are different types of nagging, as well as different parental reactions to the nagging. Idell (1999) identifies the following two (2) types of nagging by children:

Persistence: Persistence nagging is described as the continual repetition of an ideal by children, with the belief that enough nagging will result in the parent or guardian purchasing the good in order to subdue the nagging. (Tato, 2004: 4)

Importance: Importance nagging by children is described as the perception by children that the demand for a product is more important than simply a want, and is intrinsically a need (although in many cases this is simply because of strategic marketing by marketing firms).

Idell (1999) also documented four (4) different types of parental reactions with regard to purchasing behaviour and classified them into the following categories:

Bare Necessities: These Parents are resilient to whining, and by virtue only respond to importance nagging. Although bare necessities parents may be affluent consumers - they require their children to make a valid case before they purchase a product or good. Thus, persistence nagging is less effective with bare necessity parents. Persistence nagging is effective with the other types of parents.

Kids' Pals: Kids' Pals are generally younger parents who are able to associate with their children. Kids' Pals will often purchase products for their children as it gives them a degree of satisfaction too. Products such as Sony PlayStation are appealing to these parents as it can be used by not only the child, but the parent too.

Indulgers: Indulgers are described by Idell (1999) as working parents who spend little time with their children. Indulgers feel that in order to make up for the time which they are not spending with their children, they must purchase capital goods in order to assuage their guilt; Indulgers are particularly prone to persistence nagging.

Conflicted: Tato (2004: 5) describes conflicted parents as parents who are unsure whether or not they should purchase consumer goods for children, but do anyway. Conflicted parents are easily swayed through persistence nagging, importance nagging as well as advertising which gives them information with regard to purchase decisions. Thus, with conflicted parents, marketers need to ensure that when creating advertisements they appeal to children and provide parents with credible information (Schlosser and Wilson, 2006: 7).

According to Lindstrom (2004: 175) tweens are described as the "richest generation" and the most influential. This influence on parental spending is of concern to marketers, who are trying to establish marketing strategies which appeal to tweens. Gunter, Oats and Blades (2005: 2) state that in 2000 Children in the United States of America contributed \$28 billion of their own money, and influenced the consumption of an estimated $\$ 250$ billion through parental spending. Marketers thus have to implement marketing strategies which appeal to both children as well as their parents if they wish to capture the tween niche market.

The market for tweens is growing at an increasing rate and firms are beginning to acknowledge the opportunity to position themselves in such a manner that their products appeal to children. Cardwell-Gardner and Bennett (1999: 45) recognise this trend and state that children are becoming the focus of marketing strategies not only because of their disposable income, but because of their "influence they exert on parental purchasing decisions". In an average month in America, 9 out of 10 American children visit a McDonalds (Schlosser and Wilson, 2006: 7) this shows the magnitude of children as consumers and the degree to which they are able to persuade parents through nagging. Beder (1998: Para 2) states that marketers not only target children because of the future money they are going to spend whilst growing up, but also because of the influence they have on their parents spending.

\section{Advertising Theory}

Belch and Belch (2007: 17) define advertising as a promotional tool which is used to effectively communicate a marketing 
strategy from an organisation to the consumer. Advertising can be used to increase sales of a product/service, promote a brand image, communicate product changes, and create a 'buzz' about the product through customer relations. When dealing with children, the aforementioned 'buzz' may result in nagging by children (Idell, 1999)

Advertising has evolved from being a tangible system (such as a red and white striped pole outside a barbers shop) to that of a more sophisticated media-orientated system which saturates the audience in images (Petley, 2002: 5). Types of advertising media include (but are not limited to):

- Print Advertising (Newspapers, Magazines, Brochures, Fliers)

- Outdoor Advertising (Billboards, Kiosks, Tradeshows and Events)

- Broadcast advertising (Television, Radio and the Internet)

- Covert/Guerrilla Advertising (Advertising in Movies)

- Celebrity Advertising (Celebrity Endorsement)

- Advertising Appeals

Once marketers have determined which medium they wish to use, they need to determine the strategy which will be adopted to best communicate with their target market with regard to Reach, Frequency and Media Impact (Masterson and Wood, 2005: 284). It is important to define and explain some of the key concepts that can help to understand the subject matter at hand.

Reach: Frequency measures the percent of the customers within the target market who are subjected to the advertisement. An ideal reach would be $100 \%$ of the target market, as this would result in the firm communicating their message to everyone of concern and would result in increased future sales. However, this is very optimistic as in most cases not all people receive the message (Masterson and Wood, 2005: 284).

Frequency: Frequency measures the amount of times a member of the target audience has the opportunity to see the particular advertisement. Marketers prefer to have a high frequency as it accentuates their message, however it is costly to flight advertisements often. Masterson and Wood (2005: 284) state that depending on the intended impact of the message the number of required viewings fluctuates. They believe that some media, such as broadcast media and outdoor advertising, require high frequency whereas high impact campaigns such as in-store promotions and dramatic ambient media require less frequent viewings.

Media Impact: Impact refers to the degree which the message is noticed and received by the target audience. Depending on the medium and requirement of the advertisement the impact may be high or low. (Masterson and Wood, 2005: 285)

"There is sufficient empirical evidence to conclude that television advertising has a modest direct effect on children's food choices" (Livingstone and Helsper, 2004: 6). Since advertising is required to effectively position an organisation towards a desired target market (Masterson and Woods, 2005: 284) it is vital that when targeting the tween market, to understand not only advertising theory, but also theory which is specific to prepubescent children.

The World Federation of Advertisers (WFA) believe that by the age of twelve, children develop concrete behaviours as consumers and are able to critically analyse advertisements and adapt their attitudes towards them (WFA, 2007: 1). However, before this age, children are not autonomous consumers and cannot create their own opinions on products. This is in accordance with Piaget's Model, which states that children fit into four categories; the sensorimotor stage (birth -2 years old), preoperational stage $(2-7$ years old), concrete operational (8 -11 years old) and formal operations stage (older than 12 years old) (Macklin and Carlson, 1999: 18).

\subsection{Ethics}

When dealing with children, the issue of ethics come in the discussion. Ethics is defined as a set of written and unwritten codes of principles and values that govern decisions and actions within a company. The debate as to whether or not it is ethical to market unhealthy goods to children has been deliberated over for decades. Singer and Singer (2001: 448) believe that the potential influence of consumption which advertisements have on children "is even more powerful [than adults], as children are less likely to look at media images with a critical eye."

Marketing critics argue that since children have less cognitive knowledge it is unfair to market goods to them (Bijmolt, Claasen and Brus, 1998; Gunther and Furnham , 1998), as they do not understand the selling intent behind adverts (McGinnis, Gootman and Kraak, 2006: 341). Macklin and Carlson (1999: 3) believe that in order to determine whether or not children are autonomous consumers, they must be assessed in terms of (a) Differentiating Advertisement 
from entertainment; (b) Understanding the persuasive nature of advertisement; (c) Understanding that advertisements may exaggerate claims and are not necessarily truthful.

Areas of advertising to children which could be perceived by consumers as unethical include (But are not limited to) the following appeal techniques:

Use of Cartoon Characters: It has been determined that children can associate not only with other humans, but with cartoon characters too. Marketers thus use cartoon characters to promote goods using bold bright colours which attract children (Smith, 2008: Para 10). Smith (2008: Para 7) states that in a survey conducted, two thirds of parents interviewed believed that the use of cartoon characters to promote food should be banned. Children not only relate to cartoon characters, but have a genuine knowledge and fascination with them.

Misleading Information: Singer and Singer (2001: 448) believe that children are more malleable than adults. By virtue of this, Singer and Singer (2001) state that misleading information has a greater influence on children's demand for a product, and could result in increased nagging.

Gifts and Rewards: An example is the happy meal which McDonalds launched in 1979 (Spurlock, 2005: Para 12). A happy meal includes a product premium in the form of a toy. Spurlock (2005) poses the question that children may be influenced by the demand for the toy rather than the demand for the meal. Children lack the cognitive ability to determine what foods are healthy and do not understand the concept of a balanced diet.

Advertising can have an adverse effect on children's psychology. This is illustrated by Clay (2000: 1) who states that "children have become convinced that they're inferior if they don't have an endless array of new products." Clay believes that the intrinsic goal of advertising is to create profits for the organisation rather than help children. This can be seen in fast food restaurants such as McDonalds who create additional demand for foods which are high in saturated fat and sodium through the use of the nag effect.

However, this does make the topic of positioning a firm specifically for children a sensitive subject which must be handled without offending people. Walker, Mullins and Larreche (2008: 36) states that, "unethical practices can damage relationships between a firm and its suppliers or customers" which can result in the long term loss of business. On the other hand however, Gunter, et al (2005: 2) state that in 2000, children in the United States of America influenced \$250 billion worth of purchases making them a niche market which marketers would be naive to neglect.

\section{Research Methodology}

Empirical research was conducted at four schools in the Pietermaritzburg area of KwaZulu-Natal to collect the required data for this article.

A non-experimental quantitative design was utilized. Non-experimental designs examine the correlation between two or more variables without establishing a control group or using an intervening variable (Kruger, Mitchell and Wellman, 2005: 93). Within the non-experimental research design, an administered questionnaire was selected. The questionnaire was administered during school hours as a 'class exercise'. An administered approach was chosen because younger children do not have the capacity to fully understand and complete a survey unassisted. Permission was obtained from the school principal or head to allow the children to attend the interviewing session.

\subsection{Questionnaire Design}

Loubser, Martins and van Wyk (1996: 215) state that there are three parameters which must be addressed before a questionnaire can be developed. Firstly, the problem must be stated; Secondly, the population to be surveyed must be defined; finally, the most optimum means of collecting data must be selected.

With regard to the survey population, the researcher elected to delimit the research to the Pietermaritzburg region of KwaZulu-Natal, South Africa. However, due to time and budgetary constraints it was unfeasible to attempt to collect data from every child within this area. Consequently, four schools were chosen. Children aged between 8 and 13 within these schools became the survey population.

The questionnaire was circulated to 784 children aged between 8 years old and 13 years old. The questionnaire included privileged information about participants, such as demographic information. However, all participants had the option to leave any section of the questionnaire blank if they chose to do so. 


\subsection{Data collection}

The data collection process was broken down into 2 stages. The first stage dealt with obtaining ethical clearance from gatekeepers while the second stage comprised the actual data collection from schools.

The first step was to obtain Department of Education (DoE) approval. This involved submitting a research proposal, intended list of schools, sample questionnaire and a letter from the organisation which the research was for (UKZN). Once DoE clearance was ascertained, meetings with school headmasters were organised in which the schools granted permission for the researcher to conduct a survey. Informed consent documents were submitted to the sample population and parents/guardians prior to any questionnaires being disseminated.

The actual data collection process took place as a "class exercise". Educators were informed that, if necessary, they could clarify a question - but they must attempt to do so without leading the respondent.

\subsection{Data analysis}

Data analysis was split into two stages; Data preparation and data analysis. During the data preparation stage, data was edited, coded and captured (Loubser, et al., 1999: 295). This involved breaking down the data in such a manner that it could be converted into a statistics management package. The researcher coded the data into a program called Statistics Package for Social Sciences (SPSS) which allows for convenient electronic processing and analysis techniques.

The data was analysed using frequency distributions, cross tabulations and Correlations. Pearson Correlations were used for interval variables and Spearman's correlations were used for ordinal variables) Objectives were answered through the use of these descriptive statistics.

\section{Effect of Nagging on Consumption Frequency}

To answer the objective of fast food restaurants marketing campaigns to insight children to nag their parents to take them for fast food. As shown in figure 1.1, The empirical survey found that when asked who normally requests fast food, the majority of respondents (52.7\%) stated that they personally requested fast food; in addition to this, it was found that $31.2 \%$ of respondents stated that their sibling was usually responsible for requesting fast food. Since both of these categories are representative of "nagging" it can be determined that $84 \%$ requests for fast food in families with children originated from the children. This shows that the Nag Effect is a justifiable concern for fast food outlets.

Figure 1.1: Who Normally Requests Fast Food?

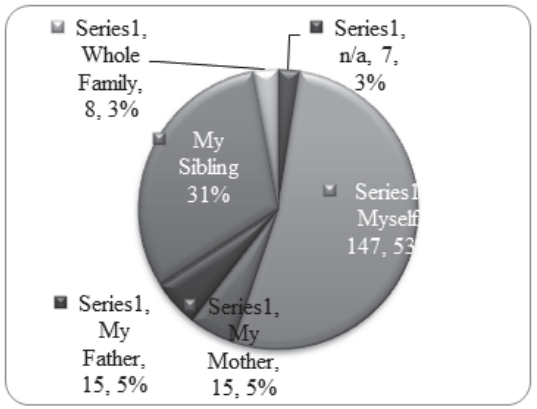

There is still the question as to whether or not nagging has an influence on consumption frequency. Researchers have argued both ways. On one hand, researchers believe that obviously the nag effect will increase consumption frequency, as parents will eventually cave to children's requests. On the other hand however, researchers such as Spungin (2004) believe that ultimately, it is the parents who make the final purchase decision and consequently nagging has a negligible effect.

The empirical research established that the latter is true for the case of fast food consumption by tweens in Pietermaritzburg. A Pearson correlation was conducted which determined the relationship between consumption frequency and who requested the fast food resulted in a low correlation coefficient of 0.037 . This showed that there is not a strong relationship between who normally demands a product and the consumption frequency. In order to ensure that 
the correlation accurately measured variables, data was entered into 3 ordinal groups; namely, tweens (children and siblings), whole family, parents. The low correlation showed that as the group changes, there is not a relative change in consumption frequency. This is shown in Figure 1.2 Below.

Figure 1.2: Consumption Frequency * Who Requests Fast Food

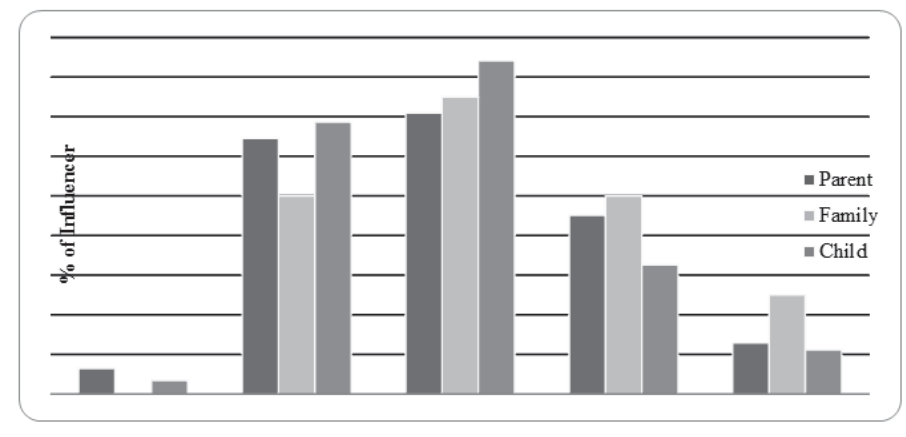

Although Figure 1.2 shows some anomalous results, research by Spungin (2004: 40) found that 96\% of parents agreed with the statement "It's up to parents to explain [that children] can't have everything they see advertised." Spungin (2004: 37) coins the term "Parent Power" to refer to the manner in which parents respond to nagging. Spungin determined that although children may pester, the majority $81 \%$ of parents would normally assess the product before making a decision, with only $14 \%$ of parents stating that they would let their child consume a product without vetting it first. The researcher believes that when parents are faced with nagging, they may concede to children, however this might just result in the next scheduled fast food purchase being cancelled (e.g. Parent buys fast food on Monday due to nagging, but then does not buy on Tuesday when he/she had planned to because they had consumed fast food already).

This article therefore argues that although the overall consumption frequency may not increase, consumption frequency at particular outlets still may experience positive growth. This was determined, as only at the top 5 restaurants which were identified by children as their favourite restaurants were toys mentioned by the respondents. Since product premiums at fast food outlets are targeted specifically at tweens, it is evident that they still do draw attention. Stuart and Kerr (2009: 3) state that a survey involving a product premiums at fast food outlets found that the leading reason why consumers would purchase a meal with a toy was habit rather than other reasons tested; "the effect of child's requests was less important" (Stuart and Kerr, 2009: 3).

\section{Relationship between Advertising Awareness and Nagging}

The function of advertising to tweens has been described by marketers such as Clay (2000: 1) as an unethical process. Clay believes that since children do not know what an advert is, they may not make autonomous decisions and the influence of the advert may be exacerbated, which could result in excessive nagging by the tween.

Consequently, in order to determine whether there is a relationship between knowledge of advertisements and nagging by tweens, respondents were asked whether or not they knew what an advertisement was and the result was correlated to who in the family generally requested fast food.

Table 2.1: Advertising Knowledge vs. Who Requests Fast Food

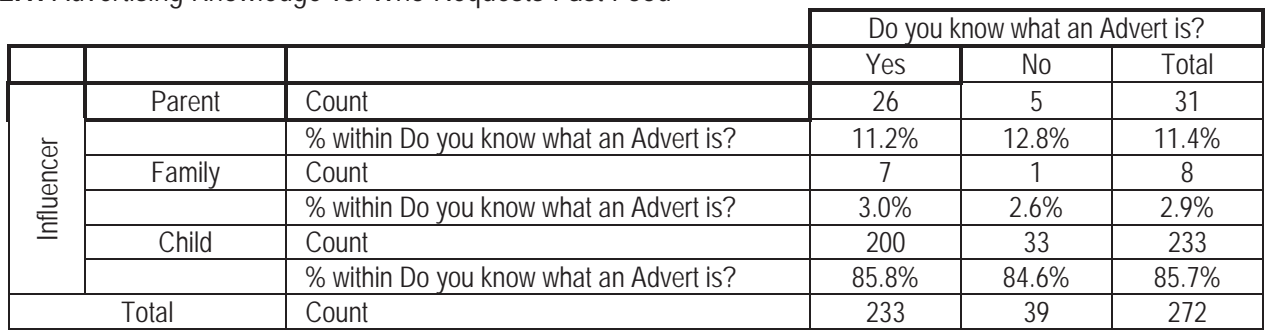


The findings outlined in Table 2.1 showed that an overwhelming majority of respondents (86\%) believed that they knew what an advert was. When this was correlated with who normally requests fast food, a Spearman Correlation coefficient variable of -0.013 was derived. This shows that there is little relationship between whether or not the tweens know what an advert is and whether or not they request fast food; this is shown in figure 2.1 below. Unfortunately, since the survey had such an insignificant amount of respondents who stated that they did not know what an advert was, the significance coefficient (Sigma 2-tailed) denoted a value of 0.829 which shows that the results are not reliable enough to make an objective conclusion.

Figure 2.1: Advertising Awareness vs. Who Nags

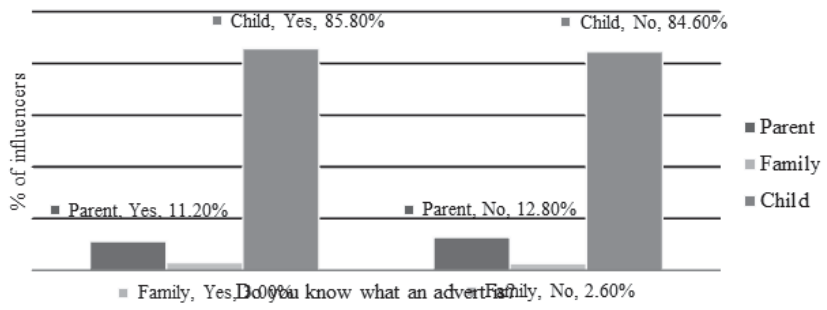

Despite the relatively low significance coefficient, figure 2.1 above shows that there is very little difference between who requested fast food and tweens knowledge of advertisements.

It is important to note that this finding does not suggest that advertising does not have a correlation with amount of nagging, but rather that children nag regardless of whether or not they have the cognition of what an advert is. Story and French (2004: 11) state that there have been numerous studies which have investigated the effects of advertisements on nagging with the general consensus that "food advertising increases the number of attempts children make to influence food purchases their parents buy".

\subsection{Nagging and Age}

Although Piaget's model can be utilised to describe the different cognitive capabilities of children, few empirical studies has been conducted to determine whether age plays a significant role in the nag effect. The model segments children into 4 different categories based on age; Sensorimotor (Birth -2 years old), Preoperational ( $2-7$ years old), Concrete Operational (8 - 11 years old), and Formal Operations (Older than 12 years old) (Macklin and Carlson, 1999: 18).

Table 3.1: Who requests Fast Food vs. Age

\begin{tabular}{|c|c|c|c|c|c|c|c|c|c|}
\hline & & Age & 8 Years Old & 9 Years Old & 10 Years Old & 11 Years Old & 12 Years old & 13 Years Old & Total \\
\hline & & get's Stage & \multicolumn{4}{|c|}{ Concrete Operations } & \multicolumn{2}{|c|}{ Formal Operations } & \\
\hline \multirow{6}{*}{ 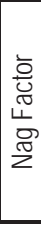 } & Parent & Count & 5 & 6 & 5 & 2 & 4 & 9 & 31 \\
\hline & & $\%$ within Age & $10.6 \%$ & $10.9 \%$ & $12.8 \%$ & $5.9 \%$ & $7.4 \%$ & $20.9 \%$ & $11.4 \%$ \\
\hline & Family & Count & 2 & 0 & 0 & 1 & 3 & 2 & 8 \\
\hline & & $\%$ within Age & $4.3 \%$ & $.0 \%$ & $.0 \%$ & $2.9 \%$ & $5.6 \%$ & $4.7 \%$ & $2.9 \%$ \\
\hline & Child & Count & 40 & 49 & 34 & 31 & 47 & 32 & 233 \\
\hline & & $\%$ within Age & $85.1 \%$ & $89.1 \%$ & $87.2 \%$ & $91.2 \%$ & $87.0 \%$ & $74.4 \%$ & $85.7 \%$ \\
\hline & Total & Count & 47 & 55 & 39 & 34 & 54 & 43 & 272 \\
\hline
\end{tabular}

A Spearman's Correlation test was run to determine whether or not there was a relationship between age and who requests fast food. The resultant correlation coefficient of -0.073 shows that although the variables are connected, the relationship between them is relatively weak. The relationship between age and nagging for the concrete operations phase and the formal operations phase are shown in figures $3.1 \mathrm{a}$ and $3.1 \mathrm{~b}$ respectively. 
Figure 3.1a: Concrete Operations Age vs. Nagging Correlation

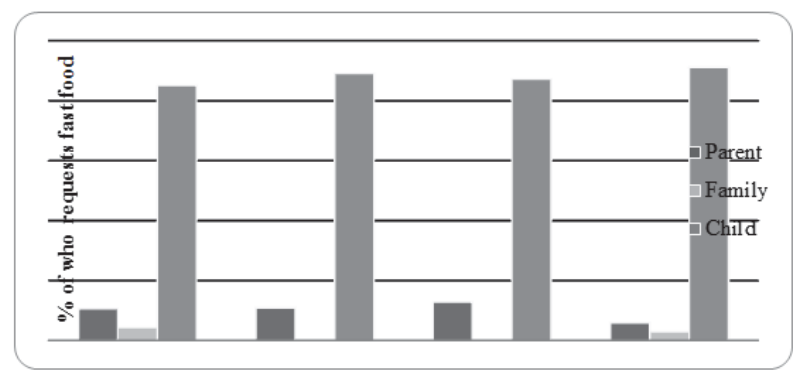

Figure 3.1a (above) shows that as age increases through the concrete operations phase of Piaget's model, there is little difference in who requests fast food.

Figure 3.1b: Formal Operations vs. Nagging Correlation

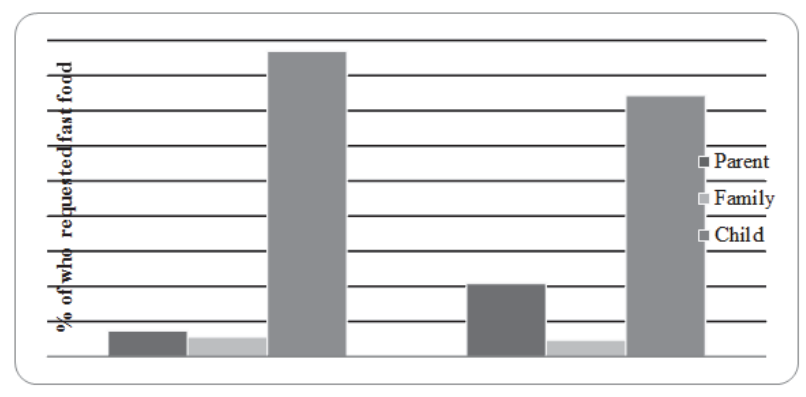

Figure 3.1b (above) shows that as age increases through the formal operations age, the amount of nagging by tweens begins to subside. From this information, it can be inferred that although there is little impact of age on nagging for children during the concrete operational stage, as children mature into the formal operations stage the amount of nagging decreases.

\section{Recommendations}

The following recommendations can be suggested for managers with regard to advertising appeals and their effect on children.

\subsection{Appeal Techniques}

The empirical survey determined that there was a significant difference in appeal techniques effect on children depending on whether or not the outlet was a take-away or a sit-in family restaurant. Family restaurants benefit more from emotional appeals such as adventure clubs, and game rooms whereas take-away outlets foster sales through the use of product appeals.

\subsection{Product Appeals}

For take-away outlets, the empirical survey determined that the paramount concern of tweens were the product appeals, with an emphasis on the taste of the product. Research conducted by Robinson et al. (2007: 794) showed that children perceive food in branded packaging to have a superior taste than food which is unbranded. Consequently, by utilising branded packaging, children will perceive your product to taste superior, while at the same time building brand awareness. 
Nutrition and variety also played a significant role in the children's selection of their favourite brand decision, and is responsible for $8 \%$ of tween brand selection. Furthermore, Spungin (2004: 37) states that parent's rate nutritional value as the most important factor which influences purchase decisions. Spungin (2004: 38) acknowledges that although parents of children under the age of two have frequent contact with health advisors, as children age the information available of a balanced diet decrease, which resulted in only 13\% of mothers knowing how many calories a 13 year old boy should consume (Spungin, 2004: 38). Thus the practice of providing accurate nutritional guides which not only show ingredients, but also provide healthy eating tips and highlight healthy constituents of the meal would have a dichotomous effect on consumption frequency. On one hand, parents would be more willing to take children to a restaurant with healthier perceived products; and on the other hand, children would prefer to eat food which is good for them.

Pricing influenced $6 \%$ of tweens selection of a favourite brand. Moreover, pricing has a direct correlation to consumption frequency. The study conducted by French (2003: 842) showed that a reduction in price had a significant impact on the quantity demanded. It was found that a decrease in price of $10 \%, 25 \%$ and $50 \%$ resulted in an increase in demand for the product of $9 \%, 39 \%$ and $93 \%$ respectively. Consequently, when setting the price of a product, it is vital to ensure that the correct price is established which results in sufficient demand while still operating with a sufficient profit margin. French (2003: 844) stated that although demand increases when pricing is lowered, often large increases in sales volume are required in order to offset the reduced mark-up.

Product Premiums are useful in developing brand loyalty with the tween market. A Pearson Correlation coefficient of 0.695 established that there is a linear relationship between the amount tweens are willing to spend on a meal without a toy relative to a meal with a toy. Research by Atkin (1978: 44) showed that premiums have the potential to influence purchase requests of children. Consequently, it is a feasible strategy to use to influence consumption. The empirical research showed that of the 12 brands identified by children, the top 5 brands with the highest brand preference were the only brands in which product premiums were mentioned. Stuart and Kerr (2009: 4) state that children often blur the product and the product premium, and since the product premium is a tangible good product recall is more significant. Consequently, the inclusion of a product premium with a child meal could increase brand preference.

\subsection{Emotional Appeals}

Emotional appeals are more effective in family restaurants rather than take away outlets. Spur for example has built strong brand loyalty through the use of their Kids Club (The Spur Secret Tribe), their kids Magazine (The Totem Pole) and their entertainment area. The impact of these emotional appeals can be gauged, as $33 \%$ of respondents who identified Spur as their favourite brand elected it based on the fun / exciting environment.

When advertising to young children, marketers such as Warren et al. (2008: 233) state that since children gradually develop logical understanding through experience, the most effective way to generate brand awareness is through the use of salient cues which the child can immerse themselves in. Gunther et al. (2005: 74) concur with Warren et al. and state that when communicating with children, peripheral cues such as bright colours, visual stimuli and jingles should be used. The fact that $7 \%$ of respondents mentioned the packaging when asked to describe a Happy Meal shows that the bright colours have made an impact on them. Marketers must thus ensure that when designing any element of the value chain which tweens will interact with, they include salient cues.

The use of cartoons as brand ambassadors in South Africa is not as effective as America. This is evident as it was established that only $59 \%$ of respondents could identify Ronald McDonald. This results in two options for marketers. On one hand, since there are no developed 'cartoon food ambassadors' in South Africa there is the possibility to create a new persona and utilise them as a promotional tool as there is no one to compete with; on the other hand, it could be as a result of lack of tween willingness to adopt a cartoon persona. If Ronald McDonald has not been successful, despite McDonald's immense marketing budget, why would another cartoon ambassador be successful?

\subsection{The Effect of Age}

Managers must pay special attention to the age of the children and the type of products or services that they are offering. Age generally has an effect on product and services consumption or usage pattern.

\section{5 knowledge of Advertisements}

It was determined that $86 \%$ of respondents believed they knew what an advert was. Cognition of advertisements was assessed based on three key components which were identified by Macklin and Carlson (1999: 3); namely the degree to 
which children understood that adverts are informative, adverts have a selling intent, and adverts are intrinsically persuasive.

The management implication of advertising to children who do not have the cognitive capability to process the advert has a dichotomous adverse effect. On one hand, the communication may be decoded incorrectly by the tween resulting in the tween not receiving the desired message which could have an adverse effect on brand perception; on the other hand, parents may feel that by advertising to children which do not have a working knowledge of advertisements, organisations are exploiting them.

The empirical research found that Piaget's model was a suitable measuring tool to determine the cognitive processing capabilities of tweens. As tweens move from the concrete operations stage to the formal operations stage, their knowledge of advertisements increases. The empirical findings found that children older than 11 (formal operation) had the greatest knowledge of advertisements.

\subsection{Age vs. Consumption Frequency}

It was found that the age group which experienced the highest consumption frequency was the 8 year old age segment. Consequently, they are the segment which is the most profitable. A Pearson correlation between age and consumption returned a correlation coefficient of -0.159 which shows that as tweens progress in age, the quantity of fast food they consume decreases marginally. Consequently, from a profit point of view - the 8 year old segment should be targeted. The 11 year old age segment showed the lowest consumption frequency and is consequently the least profitable.

\subsection{The Nag Effect}

The study found that the correlation between consumption frequency and nagging was very low. What this entails that instead of generating additional consumption in the fast food industry, nagging rather simply determines where the tween will consume. The research showed that the item which generated the highest nag effect was a product premium. Consequently, in order to generate nagging, fast food outlets should include product premiums with tween meals.

\section{Conclusion}

The empirical findings suggest that despite child demand driving $84 \%$ of fast food requests, consumption frequency was not affected by these requests. This is in accordance with findings of researchers such as Spungin (2004: 38) who found that because the ultimate purchase decision is the parents, the impact of nagging is reduced; and Stuart and Kerr (2009: 3) who found that other factors such as habits had a more significant influence on consumption frequency rather than the nag factor.

The article therefore can conclude that advertising awareness does not always influence nagging in children in relation to their consumption behaviour. Children requested fast food at the same frequency irrespective of whether or not they had a working knowledge of what constitutes an advert.

Finally, it can also be argued that during the concrete foundation stage of children, age does not play a significant role in the frequency of nagging, with frequency distributions taking a haphazard distribution. However, as children mature into the formal operations phase, the frequency of nagging decreases.

\section{References}

Beder, S (1998) Marketing to Children [Online] Available From: http://www.uow.edu.au/arts/sts/sbeder/children.html [Date Accessed: 05/03/2009]

Belch, E. Belch, M. (2007) Advertising and promotion: An integrated marketing communication perspective 7th Edition. New York: McGraw-Hill Irwin

Bijmolt,T. H. A., Claassen,W.,\& Brus, B. (1998). Children's understanding of TV Advertising: Effects of age, gender, and parental influence. Journal of Consumer Policy. Vol 21(1) [pp 171-194]

Cardwell-Gardner, T. Bennett, J.A (1999) Television advertising to young children: An exploratory study. Communicare. Vol 19 (1)

Clay, R (2000) Advertising to Children: Is it Ethical? Monitor on Psychology. Vol 31(8). Washington: APA [pp 1-8]

Gunter, B. Oates, C. Blades, M. (2005). Advertising to children on TV. New Jersey: Lawrence Erlbaum Associates

Hamilton, C. (2006) The Intensification of Consumerism and Reactions Against It. The Australia Institute Vol 1 (1). [pp 1-9]

Idell, C (1999) The Nag Factor. Los Angeles: Western International Media

Kruger, S. Mitchell, B, Wellman, J. (2005) Research Methodology. 3rd Edition. Cape Town: Oxford University Press 
Lindstrom, M (2004) Branding is no longer child's play! Journal of Consumer Marketing. Vol21 (3). Emerald publishing group [pp 175182]

Loubser, M. Martins, J. Van Wyk H. (1999) Marketing Research: A South African Approach. 1st Edition. Pretoria: Unisa Press

Macklin, C. Carlson, L (1999) Advertising to Children: Concepts and Controversies. California: Sage

Masterson, G. Wood, E. (2005) Innovative Marketing Communication. Oxford: Butterworth-Heinemann

McGinnis, M. Gootman, J. Kraak, V. (2006) Food marketing to children and youth. USA: Institute of Medicine

Petley, J. (2002) Advertising. London: Hodder Wayward

Phillips (1999) C'mon, Mom! Kids Nag Parents to Chuck E. Cheese's [Online] Available From: http://findarticles.com/p/articles/ mi mOFVE/is 9 4/ai 54631243/ [Date Accessed: 03/04/2009]

Roper, S. Shah, B. (2007) Vulnerable consumers: the social impact of branding on children. Equal Opportunities International. Vol 26(7) [pp 712-728]

Schlosser, E. Wilson, C. (2006) Chew on this. New York: Houghton-Miffler

Singer, D. Singer, J. (2001) Handbook of Children and the Media. London: Sage

Smith, R. (2008) Cartoon Characters Promote Unhealthy Food to Children [Online] Available From: http://www.telegraph.co.uk/news /3116057/Cartoon-characters-promote-unhealthy-food-to-children.html [Date Accessed: 04/04/2009]

StatsSA (2009) Food and Beverages (Preliminary) statistical release. [PDF] Available From: http://www.statssa.gov.za/Publications/ P6420/P6420January2009.pdf [Date Accessed: 20/04/2009]

Stuart, H. Kerr, G. (2009) Marketing to Children: The Premium effect. Australia: Queensland Univeristy of Technology. [pp 1-7]

Spungin, P. (2004) Parent Power, not Pester Power. Young Consumers: Insight and Ideas for Responsible Marketers. Vol 5(3) [pp 3740]

Spurlock, M. (2005) The truth about McDonalds and Children. [Online] Available From: http://www.commondreams.org/views05/052220.htm [Date Accessed: 17/04/2009]

Story, M. French, S. (2004) Food Advertising and Marketing Directed at Children and Adolescents in the US. International Journal of Behavioural Nutrition and Physical Activity. Vol 1(3) [pp 1-17]

Tato. (2005) The Nag Factor [Online] Available From: http://everything2.com/index.pl?node_id=1701833 [Date Accessed: 05/04/2009] Walker, O. Mullins, J. Larreche, J (2008) Marketing Strategy: A decision-focused approach. Asia: McGraw-Hill

WFA - World Federation of Advertisers (2007) Food and beverage advertising to children: When is a child a child? [PDF] Available From: http://www.wfanet.org/pdf/adv_papers/when_is_a_child_a_child.pdf [Date Accessed: 20/03/2009] 